\title{
Time to Refuel the Conceptual Discussion on Public e-Services: Revisiting How e-Services Are Manifested in Practice
}

Ida Lindgren and Ulf Melin

The self-archived version of this journal article is available at Linköping University Institutional Repository (DiVA):

http:/ / urn.kb.se/ resolve?urn=urn:nbn:se:liu:diva- 140709

N.B.: When citing this work, cite the original publication.

Lindgren, I., Melin, U., (2017), Time to Refuel the Conceptual Discussion on Public e-Services:

Revisiting How e-Services Are Manifested in Practice, 16th IFIP WG 8.5 International Conference, EGOV 2017, St. Petersburg, Russia, September 4-7, 2017, Proceedings, , 92-101.

https:// doi.org/ 10.1007/ 978-3-319-64677-0_8

Original publication available at:

https:/ / doi.org/ 10.1007/ 978-3-319-64677-0_8

Copyright: www.springer.com 


\title{
Time to refuel the conceptual discussion on public e-services - revisiting how e-services are manifested in practice
}

\author{
Ida Lindgren $^{1 \text { [0000-0002-4735-8697] }}$ and Ulf Melin ${ }^{1[0000-0002-2784-863 X]}$ \\ ${ }^{1}$ Linköping University, SE-581 83 Linköping, Sweden \\ ida.lindgren@liu.se; ulf.melin@liu.se;
}

\begin{abstract}
There are various models and frameworks describing the nature of eservices in the public sector. Many of these models are based on previous conceptualizations and have evolved over time, but are first and foremost conceptual creations with weak empirical grounding. In the meantime, practitioners in the field have continued to further develop e-services, and new advancements in technology have enabled new solutions for e-services. In the light of advancements in practice, and the limitations seen in current conceptual work concerning public e-services, we identify a need to refuel the conceptual discussion on eservices in the public sector by empirically investigating how e-services can be manifested in practice. The aim of this paper is to illustrate the possible variations of e-services in practice, and to discuss this variation in relation to the conceptual representation of the phenomenon. Based on qualitative interviews with employees involved with e-service development and provision at a large governmental agency, we illustrate that an 'e-service' can take on many different forms within an organization; ranging from downloadable forms, to complicated self-service systems that require expertise knowledge and IT-systems with specific processing capacity. The notion that all services mediated through a website can be understood under one general umbrella term, without further categorization, needs to be challenged.
\end{abstract}

Keywords: e-services, public sector, conceptual model.

\section{Introduction}

Providing public services online, e-services, has long been promoted as a way to innovate public sector operations and to open up for a more transparent and democratic society. Governmental agencies and other public organizations have spent considerable efforts on developing e-services as a substitute or complement to traditional, manual or face-to-face, services [2]. As a result, e-services have become a routinely used channel of communication and interaction between citizens and public administrations [4]. Still, both practitioners and researchers in the field claim that there is a very large variation in the extent to which e-services are implemented in the public sector, and in the quality of these services [8]. Developing e-services, and ensuring their uptake, has 
proven difficult and the underlying reasons for why e-service development is challenging are of course many. Lack of sufficient resources and know-how is highlighted, as well as insufficient understanding and involvement of important stakeholders in the development process [3].

Some scholars have pointed to the conceptual vagueness of the e-service concept in itself, and claimed that the conceptual confusion around this phenomenon is one reason for slow advancements in this field [10]. Lindgren and Jansson [18] illustrate how the concept of public e-services has suffered from "conceptual stretching" [23], i.e. vague conceptualization; it can be everything or nothing (cf. [21]). The conceptual vagueness of the phenomenon has gained attention in the research literature; today, there are various models and frameworks describing the nature of e-services $[10 ; 11]$. These models are typically conceptual constructions and we identify a lack of grounding of these models in practice. In the meantime, practitioners in the field have continued to further develop e-services and new advancements in technology have enabled new solutions for e-services, e.g. improved performance concerning processing and storage, as well as increased use of mobile devices [4]. In the light of recent advancements in practice, and the limitations identified in current conceptual work concerning public e-services, we argue for a need to refuel the conceptual discussion on e-services by empirically investigating how e-services can be manifested in practice.

The aim of this paper is to illustrate possible variations of e-services in practice, and discuss this variation in relation to the conceptual representation of the phenomenon. This work is built on the assumption that there are different types of e-services, and that there is a gap between how we discuss public e-services in the research literature, and the nature of the e-services provided by public organizations. In order to investigate this assumed gap between how e-services are perceived in literature and practice, our work departs from three different conceptual models and one particular public organization.

\section{Method}

The empirical part of this paper is based on a single qualitative and interpretative case study (cf. [27] [19]) focusing on how a Swedish governmental agency (The Swedish Transport Administration) works with e-services. This paper is written in the context of a research project investigating the development and use of e-services in that particular agency. The aim of the project is to better understand how public sector organizations can work with e-service development in order to ensure that these services add value for both internal and external stakeholders. Focus include investigating how eservice development is governed and on conceptual refinement of "e-service" as a general concept. The initiatives described in this paper can be categorized as an act of engaged scholarship [26], meaning that we have tried to combine theoretical and conceptual development with efforts to contribute to the government agency's problem-solving activities. 
Qualitative data generation and analysis was conducted in an iterative manner and include three different sources;

- Document studies were performed to get an overview of the governmental agency's work with e-services. We have focused especially on three strategy (policy) documents that steer the development and provision of e-services in the organization; (a) the IT Strategy, (2) the Digitalization Strategy, and (3) the Service Strategy.

- 25 semi-structured interviews [20] where conducted over a period of 21 months (March 2015-Dec 2016) with representatives from several business areas and hierarchical levels at the headquarters and different divisions of the organization (e.g. strategic planning, communications, IT-department, controlling, customer service, business development). 17 of the interviews were conducted face-to-face, and eight were conducted using telephone. The interviews were guided by open ended questions and focused on e.g. how the respondents define e-services; how they interpret the strategies mentioned above; management issues linked to e-services; and present challenges and possibilities associated with e-services.

- A hermeneutic literature review [5] was used to increase our understanding of concepts and the managerial challenges of e-service development, provision, and use. We have explored themes that surfaced continuously during the emerging analysis of the empirical data from interviews and documents from the government agency. The results of this review are presented in the next section.

The analysis was performed during the research period when interviews were transcribed (partially, when deeper knowledge were needed) and the responses were categorized inductively, as a part of a content analysis approach [15]. Working with the analysis in this way is an example of a reflexive research process [1], generating categories based on the empirical data while using theory as a guide (e.g. previous research on conceptualizations of public e-services) [27].

\section{Public e-services in the e-government research literature}

The literature on e-services in the public sector is growing and includes a large number of various concepts used more or less synonymously, such as public e-service [13], eservice [14], digital service [22], e-Public-Service [17], e-government service [9], and Web site channel [6]. As a response to this variation in terminology, Lindgren and Jansson [18] presented a generic framework for understanding public e-services as having three dimensions. First, a public e-service must be understood as a service process, that should create some value for both user and supplier. Second, this service process is mediated through some internet-based and interactive IT artifact, that is integrated with other IT-systems in the supplying organization. Third, e-services provided by public organizations must be understood as public services mediated online, and thereby as access to governments and public organizations per se [12]. For example, this last dimension entails a set of public values, as well as specific regulatory frameworks and relationships between government and citizen, to be considered. 
Other scholars have identified the need for more detailed classifications or characterizations of e-services in the public context. The result is considerable literature on how to distinguish one type of e-service from another, first and foremost with regards to their so-called maturity. The idea of assessing maturity stems from the seminal paper by Layne and Lee [16], and has later been manifested in a number of different frameworks. Although the wording is slightly different in these models (e.g. [28] [25]), four typical stages can be identified;

1. a website providing information about the agency and its services,

2. a website providing interactive information about the agency and its services, or providing the possibility to contact people and get further information through communication,

3. a website providing functions allowing the visitors to hand in and retrieve person-al information, and

4. a website with network functions for proactive and joined-up services involving several agencies and institutions, for handling complete service transactions.

According to critics of these models (e.g. [7]; [10]; [4]), stage models represent a naïve and techno-centric view on technology in which the maturity characteristics of an e-service are assessed without investigating the actual demand for and use of the service. The evolutionary aspect also implies that the higher stages are inherently better than the lower. The result of this kind of model is that policy makers may be deceived into using the stage models in a normative manner and thereby strive for higher stages on weak, or even false, grounds [7].

More recently, Jansen and Ølnes $[11 ; 10]$ conducted a rigorous review of current literature on public e-services, and presented a framework for categorizing digital interaction between government and citizens/businesses. In contrast to other similar frameworks, Jansen and Ølnes [10] focus not only on the mode of interaction, but also on the purpose, content, and outcome of the interaction for both provider and receiver. The main categories in their framework are the following;

1. Simple, one-way information provision - provide documents to users for down-loading.

2. Two-way communication and information provision - provide specific information services on user request.

3. Dynamic, secure interaction between user and system - initiate a well-defined data handling process, complete an electronic form.

4. Secure transaction and contraction - carry out a specific task, regulated by law, which may be part of public service provision.

5. Complete transaction process - initiate and execute a complete set of tasks, e.g. case handling.

6. Support functions - execute a process that is necessary/required for executing a task, e.g. $\log$ in, eSignature.

These three frameworks presented above focuses on different aspects of public eservices. The dimensions presented by Lindgren and Jansson [18] tries to capture the 
common denominator of the different processes/systems included in the public e-service concept. The maturity stage models, e.g. Wimmer [28], captures different degrees of interactivity seen in different public e-services. And finally, the work by Jansen and Ølnes $[10 ; 11]$ describes different modes of interaction, and the purpose, content, and outcome of this interaction for both provider and receiver. We now turn to our empirical example, to illustrate and analyze how public e-services can be manifested in practice.

\section{$4 \quad$ E-services at the Swedish Transport Administration}

The Swedish Transport Administration is a government agency responsible for longterm planning of the transport system for all types of traffic, as well as for building, operating, and maintaining public roads and railways. The organization has approximately 6.500 employees and is organized in different divisions and geographic regions in Sweden. The organization was formed in 2010, as a consequence of a merger between two agencies; where one agency was previously responsible for roads, and the other for railways. Today, the agency is also responsible for administering the theoretical and practical tests needed to receive a driving license and a taxi driver badge, as well as the theoretical test for the professional know-how needed for a transport license and certificate of professional competence [24].

The organization is divided into a number of departments and is characterized by the participants as a classic 'silo' organization, in which the various departments govern much of their own work. Each department is responsible for the development and provision of its own e-services, but these e-services are then accessed from a shared website (the official website of the organization). Looking at the website, the organization provides a very large number of e-services. Some respondents claim that they provide around 80 different e-services, but since the responsibility for the e-services is spread across various actors in the organization, it is difficult to get a comprehensive overview of the exact number of e-services provided by the organization. In addition, several participants report that there is an ongoing discussion in the organization as to what the 'e-service' concept means; despite the fact that there is a definition of 'e-service' adopted in the organization that can be found on their intranet: "E-service. A service that is provided through an electronic interface, and that is completely or partially delivered electronically. An e-service can for example provide information directly on the website, be a part of a case handling process, and sometimes demand log in. Downloadable forms, or other documents that are printed and saved in the computer to be sent separately as a letter or email, are not considered to be e-services. Hyperlinks to e-mail available on the website are also not considered as e-services." (our translation from Swedish).

When interviewing employees in the organization, we asked all participants to describe how e-services are manifested in their organization. In the organization, all eservices are accessible from a single webpage, with an underlying hierarchical tree structure of webpages. Looking at the site where all e-services are presented, alongside the interview material, we see that the e-services provided by the Swedish Transport 
Administration can be divided into five different types. We have extracted these types inductively from the empirical material and labelled them as follows:

1. Information e-service - a link that gives access to forms and documents.

2. Automated (self-service) e-service - an interactive interface that enables self-service for the user, with no human involvement in the back-office.

3. Mediating e-service - an interactive interface that mediate/is part of a service process, in which the user indirectly interacts with a case handler.

4. e-Service portal - an interactive interface that presents several related e-services together.

5. Open data - API's provided online that other organizations can download and use.

The first type, information e-service, refer to forms and documents made available on the website. Most participants add that these documents are not 'proper' e-services according to the organization's definition, but that these documents are still made accessible on the same web-site (context) as the other e-services. The second type, automated (self-service) e-service, refers to e-services with no human involvement in the back-office parts of the system. In this organization, there are only a limited amount of automated e-services provided and these are typically directed towards a set of wellknown professional users that are frequent users of these particular services. One example is an e-service for administrating special transport permits for heavy goods on the road, which transport companies can use in a self-service way. The third type of eservice above, mediating e-service, refers to an e-service that is part of a larger service process, in which the user indirectly interacts with a case handler. This is perhaps the archetype of e-service. In this organization, the complexity of these services ranges from uncomplicated forms in which citizens can fill in information to be handled by case handlers at the administration, to very complex systems in which railway operators can plan and apply for capacity on the railway infrastructure. The last example requires both expert users and very specific IT-systems on both the user and supplier side, concerning both software and processing capacity. The forth type, e-service portal, refers to a one-stop-shop made up by several related e-services. The e-service portals are typically directed to the administration's contract customers. The services provided within the portal can be of all of the different types above. An example of such an e-service portal is a portal directed towards railway operators, in which the service for planning and applying for railway capacity mentioned above is included. The last type, open $d a t a$, refers to the open data offered by the organization. In this particular organization, a recent decision has been made to perceive Open Data as a service, and hence also as an e-service. The open data provided through API's include data sets covering maps, traffic data (e.g. for public roads, railways, and ferries), and basic facts of the organization. In a sense, Open Data could be understood as the first type of e-service, information e-service, but both technical solution and content is different from the typical documents provided in the first type of e-service. 


\section{Discussion}

As can be seen in the categorization above, a 'public e-service' at the Swedish Transport Administration can refer to many different kinds of services and technical solutions. The inductive categories are similar to the generic e-service models provided in the literature. We soon identified that there were conceptual challenges related to e-services in the organization too; just as in the literature. The general e-service definition adopted by the organization includes all inductively generated types, except for the first; information e-service. But when you look closer at the definition, it seems to refer to any kind of interface on their website, except those that link to a down-loadable document or email. Interestingly, in their work practice, everything online that has some interactive feature is treated in terms of being an e-service on the organizational website. In this particular organization, the 'e-service' concept hence becomes the kind of stretched term that Lindgren and Jansson [18] are describing; it means just about anything that is provided online. For the participants that are working with the actual development and provision of these e-services, this definition is not informative and even creates problems. It does matter what kind of e-service you have at hand; e.g. it matters a great deal when it comes to e-service policy, development, provision and use if the e-service is used (1) to perform and deliver a fully automated decision; (2) as part of a service process involving a case handler; (3) to be part of a set of interrelated e-services, presented together in a portal; or (4) to present a packaged data set as open data. It also matters if the user is known, such as professional contract customers, or if the e-service is directed towards the more vaguely understood citizen or an unknown entrepreneur using open data. This in turn brings different consequences for how to understand what capabilities for e-service development and delivery are needed in the organization concerning service architectures, processes, policies, and reference models able to consider specificities of the local context [4].

The inductively generated categories above show many similarities with the maturity stage models; with the important difference that there are no normative connotations regarding the value of the respective kind of e-service. When comparing the framework presented by Jansen and Ølnes [10] with the inductively generated categories, we see that the first category in our inductive categorization, 'information e-service', matches with the first one in Jansen and Ølnes' framework, 'simple one-way in-formation provision'. But thereafter, it is clear that our inductively de-rived categories are differentiating e-services in a different way. Applying Jansen and Ølnes' framework on e-services in our case organization would help describe the mode of interaction for each eservice under study. However, their framework does not include any aspects concerning type of users involved, nor the notion of Open Data as an e-service. According to the framework presented by Jansen and Ølnes, open data access could indeed be classified as 'simple one-way provision of information'; but open data provision requires a lot of work behind the scenes, in comparison to uploading a form online. Considering how much work the Swedish Transport Administration puts into the packaging of their data in API's, it seems reasonable to add this type to our understanding of public eservices. In sum, each model and categorization discussed in this paper, including the 
inductive categories, captures certain - and slightly different - aspects of public e-services. But they also leave other aspects out of the description; none of these models/categorizations seem to be exhaustive or useful if used in isolation.

\section{Concluding remarks and future research}

Our analysis is based on a limited amount of literature and one single case. Still, several interesting points can be made when investigating similarities and differences between the theoretically driven conceptualizations of public e-services in the research literature, and how e-services can be manifested in practice. Above, we illustrate that an 'eservice' can take on many different forms within an organization; ranging from simple downloadable forms, to complicated self-service systems that require expertise knowledge and IT-systems with specific processing capacity from both user and supplier. The notion that all services mediated through a website can be understood under one general umbrella term, without further categorization, must therefore be challenged. There seems to exist a need for a general definition that can be used to understand the core of the public e-service concept; but in order to understand how public eservices can play out in practice, we need more detailed characterizations of the concept. The existing models presented for this purpose capture various aspects, but are still limited. We argue for a more comprehensive and scalable typology that can be used to categorize public e-service for multiple purposes. For example, the models/typologies present today lack information on (1) type of technical solution, (2) type of public service, as well as (3) type of user. We also identify a need to separate the types of public e-service from the normative notion that one type is inherently better than the other. For this purpose, we would like to call for further empirical investigations of how e-services are manifested in practice. By refueling the conceptual discussion on public e-services with further inductively induced categorizations of the phenomenon - as both process and technology - better conceptualizations can be made that, in turn, can be used to address the prevailing challenges with public e-service development.

\section{$7 \quad$ Acknowledgements}

This work was supported by the Swedish Transport Administration.

\section{References}

1. Alvesson, M. and Sköldberg, K. 2009. Reflexive methodology: new vistas for qualitative research, 2nd ed., SAGE, London.

2. Ancarani, A. (2005). Towards quality e-services in the public sector. The evolution of web sites in the local public service sector. Managing Service Quality, 15(1), 6-23.

3. Axelsson, K., Melin, U. \& Lindgren, I. (2013). Public e-services for agency efficiency and citizen benefit - findings from a stakeholder centred analysis. Government Information Quarterly, 30(1), 10-23. 
4. Bertot, J., Estevez, E., and Janowski, T. (2016). Universal and contextualized public services: Digital public service innovation framework, Government Information Quarterly, 33(2), 211-222.

5. Boell, S. and Cecez-Kecmanovic, D. (2014). A Hermeneutic Approach for Conducting Literature Reviews and Literature Searches. Communications of the Association for Information Systems, 34(1), 257-286.

6. Ebbers, W. E., Pieterson, W. J., \& Noordman, H. N. (2008). Electronic government: Rethinking channel management strategies. Government Information Quarterly, 25(2), 181201.

7. Goldkuhl, G. \& Persson, A. (2006). From e-ladder to e-diamond - re-conceptualising models for public e-services. Proceedings of the 14th European Conference on Information Systems (ECIS2006), Göteborg, Sweden.

8. Jacobson, D.I. (2016). Adopting and Refining e-services - the Role of Organization Size. Public Organization Review, 1-13

9. Jansen, J., de Vries, S. \& van Schaik, P. (2010). The Contextual Benchmark Method: Benchmarking e-Government services. Government Information Quarterly, 27(3), 213-219.

10. Jansen, A. \& Ølnes, S. (2014). The muddy waters of public e-services - the use and misuse of the concept and how to get out of the maze. Systems, Signs \& Actions, 8.

11. Jansen, A. \& Ølnes, S. (2016). The Nature of Public e-Services and their Quality Dimensions. Government Information Quarterly, 33(4), 647-657.

12. Jansson G, \& Lindgren I (2012), Putting "Public" Back into Public e-Services: A Conceptual Discussion. In Scholl H.J., et al. (Eds.), Electronic Government and Electronic Participation. Joint Proceedings of Ongoing Research and Projects of IFIP EGOV and IFIP ePart 2012. Trauner Verlag.

13. Karlsson, F., Holgersson, J., Söderström, E. \& Hedström, K. (2012). Exploring user participation approaches in public e-service development. Government Information Quarterly, 29(2), 158-168.

14. Kaisara, G. \& Pather, S. (2011). The e-Government Evaluation Challenge: A South African Batho Pele-aligned service quality approach. Government Information Quarterly, 28(2), 211-221.

15. Krippendorff, K. (2004). Content Analysis: An Introduction to Its Methodology, 2 ed. SAGE Publications, Thousand Oaks.

16. Layne, K. \& Lee, J. (2001). Developing fully functional E-government: A four stage model. Government Information Quarterly, 18(2), 122-136.

17. Lenk, K. (2002). Electronic Service Delivery - A driver of public sector modernization. Information Polity, 7, 87-96.

18. Lindgren, I. \& Jansson, G. (2013). Electronic Services in the Public Sector: A Conceptual Framework. Government Information Quarterly, 30(2), 163-172.

19. Myers, M.D. (2009). Qualitative Research in Business \& Management, Sage Publications.

20. Myers, M.D. \& Newman, M. (2007). The qualitative interview in IS research: Examining the craft, Information and Organization, 17(1), 2-26.

21. Pollitt, C. (2011). Mainstreaming Technological Change in the Study of Public Management. Public Policy and Administration, 26(4), 377-397.

22. Re, B. (2010). Quality of (Digital) Services in e-Government. PhD thesis, School of Advanced Studies - Doctorate course in Information science and complex systems (cycle XXII). University of Camerino, Italy.

23. Sartori, G. (1970). Concept Misformation in Comparative Politics. The American Political Science Review, 64(4), 1033-1053. 
24. The Swedish Transport Administration, http://www.trafikverket.se/en/ (Accessed January 12, 2017)

25. Statskontoret (2000). The 24/7 Agency. Criteria for 24/7 Agencies in the Networked Public Administration. Report no. 2000:41.

26. Van de Ven, A.H. (2007). Engaged scholarship - A guide for organizational and social research, Oxford University Press.

27. Walsham G. (1995). Interpretive case studies in IS research: nature and method, European Journal of Information Systems, 4(2), 74-81.

28. Wimmer, M. (2002). Integrated service modelling for online one-stop government. Electronic Markets, 12(3), 149-156. 